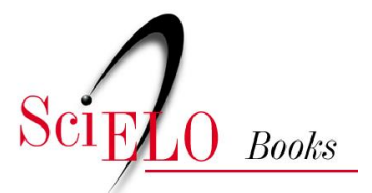

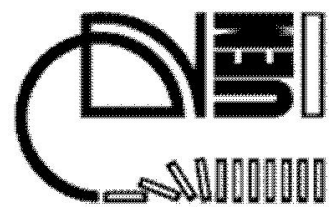

\title{
4 Comunidades quilombolas no Paraná
}

\author{
Angelo Priori \\ Luciana Regina Pomari \\ Silvia Maria Amâncio \\ Veronica Karina Ipólito
}

PRIORI, A., et al. História do Paraná: séculos XIX e XX [online]. Maringá: Eduem, 2012.

Comunidades quilombolas no Paraná. pp. 47-58. ISBN 978-85-7628-587-8. Available from SciELO Books $<$ http://books.scielo.org $>$.



All the contents of this chapter, except where otherwise noted, is licensed under a Creative Commons Attribution-Non Commercial-ShareAlike 3.0 Unported.

Todo o conteúdo deste capítulo, exceto quando houver ressalva, é publicado sob a licença Creative Commons Atribuição Uso Não Comercial - Partilha nos Mesmos Termos 3.0 Não adaptada.

Todo el contenido de este capítulo, excepto donde se indique lo contrario, está bajo licencia de la licencia Creative Commons Reconocimento-NoComercial-CompartirIgual 3.0 Unported. 


\section{4 \\ Comunidades quilombolas no Paraná}

\section{A escravidão no Brasil}

Por mais de três séculos o Brasil vivenciou as práticas de um intenso regime escravista. A inserção de negros no país, ainda que de forma vil e desumana, exerceu papel fundamental na formação da nossa sociedade. Os costumes e práticas daqueles ajudaram a moldar a rica diversidade étnica e cultural do povo brasileiro. Seja por meio da culinária, da medicina alternativa ou da própria língua, os valores africanos são passados de geração em geração e se fazem presentes em todo o país.

No Paraná não podia ser diferente. Apesar de ter sido menos intensa do que nos grandes centros econômicos, como Pernambuco, Minas Gerais e São Paulo, a presença de escravos africanos em território paranaense está longe de ser considerada insignificante. Prova disso são os dados levantados pelo grupo de trabalho Clóvis Moura (GTCM, 2010), responsável pelo levantamento de dados sobre comunidades negras e remanescentes de quilombos, por meio de uma pesquisa de campo realizada entre os anos de 2005 e 2010 em diversas cidades do Estado, cujo objetivo é o resgate histórico desses locais.

Foram mais de 300 anos de escravidão, de trabalho compulsório, de ausência de liberdade, que sustentaram a economia nacional e inseriram 
o Brasil no mercado mundial, possibilitando o enriquecimento da elite colonial. Fosse nas lavouras de cana e engenhos de açúcar, na extração de minérios e nas plantações de café, ou nos centros urbanos, a presença do escravo era uma constante. Segundo Adelmir Fiabiani:

O Brasil foi uma das primeiras nações do novo mundo a organizar o escravismo e a última a concluí-la. Também foi ali que desembarcou o maior número de africanos escravizados [...]. Praticamente não há lugar deste imenso território que não tenha conhecido o trabalho do trabalhador feitorizado (2005, p. 21-22).

As condições de sobrevivência e trabalho de um escravo eram extremamente precárias. A grande maioria era destinada às lavouras, onde chegavam a trabalhar $18 \mathrm{~h}$ por dia. Nas minas de ouro a situação era ainda pior em decorrências do ambiente e dos constantes acidentes de trabalho. Somam-se a isso uma alimentação exígua e a utilização, em larga escala, da violência, por meio dos mais variados castigos para disciplinar os negros e mantê-los obedientes. Não é de se admirar que a expectativa de vida útil desses homens não passasse de uma dezena de anos.

Ao contrário do que muitos pensam, até mesmo pela falta de documentação sobre o assunto, os escravos não se submeteram docilmente a tal dominação. Fiabiani ressalta a ideia de que:

A resistência servil surgiu como produto da contradição social de classes, quando o produtor escravizado, consciente ou inconscientemente inconformado com a apreensão e exploração desapiedada de sua força de trabalho, resistiu contra ela das mais diversas formas $(2005$, p. 22).

A resistência se dava por meio de atos como a paralisação do trabalho, a sabotagem de máquinas e ferramentas, o aborto por parte das mulheres que não desejavam que seus filhos nascessem em cativeiro, incêndio de plantações e, até mesmo, o suicídio e o assassinato de feitores e senhores. 
Entretanto, a forma mais comum de resistência à escravidão eram as fugas. $\mathrm{Na}$ maioria das vezes, os escravos se misturavam à população mestiça local ou se escondiam nas florestas e serras, locais de difícil acesso, onde acabavam desenvolvendo verdadeiras comunidades. Ali os africanos viviam da caça, pesca, artesanato e uma agricultura de subsistência que propiciava determinado comércio com as regiões vizinhas. Esses locais receberam diferentes nomes. Os mais comuns são mocambo e quilombo, palavras de origem africana que significam lugar de pouso ou acampamento.

O quilombo era um espaço de resgate e afirmação de identidade étnica e cultural. Nele, os quilombolas tinham liberdade para cultuar seus deuses e manter suas crenças e tradições. Levando-se em conta que esses núcleos de resistência se espalharam por todo o território, Clóvis Moura defende a ideia de que "a quilombagem no Brasil era fruto das contradições estruturais do sistema escravista e refletiam na sua dinâmica, em nível de conflito social, a negação desse sistema por parte dos oprimidos" (1987, p. 13).

É essencialmente com essas pequenas unidades de subsistência e reafirmação cultural que trabalharemos adiante. Mais especificamente, vamos destacar comunidades de remanescentes africanos, localizadas no Estado do Paraná, que ficaram mergulhadas no esquecimento durante décadas. Sem qualquer apoio ou reconhecimento por parte do Estado, a maioria desses locais corre o risco de perder completamente seu legado histórico.

\section{Comunidades quilombolas no Paraná}

Certamente o leitor já ouviu falar sobre o quilombo dos Palmares e seu lendário líder, Zumbi, símbolo da resistência contra a escravidão. Todo ano, no dia 20 de novembro, aniversário de sua morte, comemora-se o Dia Nacional da Consciência Negra. O que muitos ainda desconhecem é que Palmares, apesar de ter sido o mais importante quilombo em termos de desenvolvimento, extensão e população, não foi o único. Assim como 
no restante do país, no Paraná também se formaram vários quilombos ou comunidades negras rurais, que existem até hoje.

As terras onde residem atualmente esses afro-descendentes possuem origens diversas. Tanto podem ser fazendas abandonadas, doações feitas a ex-escravos, pagamento por serviços prestados ao governo, ou, até mesmo, terras compradas por negros forros. Houve também casos de terras que pertenciam a ordens religiosas e foram deixadas sob a administração de ex-escravos no início da segunda metade do século XVIII, como é o caso da fazenda Capão Alto, no município de Castro.



Figura 1: Mapa de localização das Comunidades Quilombolas do Estado do Paraná

Fonte: GTCM (2010).

O reconhecimento desses territórios no país surgiu, pela primeira vez, com a promulgação da Constituição Federal de 1988, por meio do artigo 68. Em 2001, pela edição de uma medida provisória, conferiu-se ao Ministério da Cultura as funções de identificar, delimitar, demarcar e titular as terras quilombolas e, à Fundação Palmares, a função de realizar os 
respectivos registros dos títulos. No Paraná, até o momento, a Fundação Palmares registrou 34 comunidades quilombolas:

Tabela 1: Comunidades quilombolas reconhecidas pela Fundação Palmares (2012)

\begin{tabular}{|c|c|}
\hline MUNICÍPIO & COMUNIDADES \\
\hline Adrianópolis & João Surá \\
\hline Curiúva & Água Morna \\
\hline Curiúva & Guajuvira \\
\hline Ponta Grossa & Comunidade Negra Rural de Sutil \\
\hline Ponta Grossa & Santa Cruz \\
\hline Castro & $\begin{array}{l}\text { Comunidade Negra Rural de Castro (Limitão - } \\
\text { Serra do Apon - Mamans) }\end{array}$ \\
\hline Guarapuava / Pinhão / Reserva do Iguaçu & Invernada Paiol de Telha \\
\hline Adrianópolis & Comunidade Negra Rural de Sete Barras \\
\hline Adrianópolis & Porto Velho \\
\hline Adrianópolis / Registro & Comunidade Negra Rural de Córrego das Moças \\
\hline Campo Largo & Palmital dos Pretos \\
\hline Doutor Ulysses & Varzeão \\
\hline Adrianópolis & Bairro Córrego do Franco \\
\hline Adrianópolis & Bairro Três Canais \\
\hline Adrianópolis & Estreitinho \\
\hline Adrianópolis & Praia do Peixe \\
\hline Adrianópolis & São João \\
\hline Bocaiúva do Sul & Areia Branca \\
\hline Candói & Cavernoso 1 \\
\hline Candói & Despraiado \\
\hline Candói & Vila São Tomé \\
\hline Castro & Tronco \\
\hline Guaira (ou Guaíra?) & Manoel Ciriáco dos Santos \\
\hline Guaraqueçaba & Batuva \\
\hline Guaraqueçaba & Rio Verde \\
\hline Lapa & Feixo \\
\hline Lapa & Restinga \\
\hline Lapa & Vila Esperança \\
\hline São Miguel do Iguaçu & Apepu \\
\hline Turvo & Campina dos Morenos \\
\hline Ivaí & Rio do Meio \\
\hline Ivaí & São Roque \\
\hline Palmas & Adelaide Maria Trindade Batista \\
\hline Palmas & Castorina Maria da Conceição \\
\hline TOTAL & 34 \\
\hline
\end{tabular}

Fonte: Fundação Palmares (2012). 
O número de habitantes desses quilombos varia, conforme demonstra a Tabela 2. Nesta tabela, inclusive, o leitor poderá ver que algumas comunidades se desdobram em vários núcleos, como são os casos das comunidades João Surá, Córrego das Moças, Serra do Apon, Mamãs, Varzeão, Invernada Paiol de Telha, Feixo, Adelaide Maria Trindade Batista e Castorina Maria da Conceição.

Tabela 2: Número de famílias e habitantes das comunidades quilombolas, reconhecidas ou identificadas

\begin{tabular}{|c|c|c|c|c|}
\hline & COMUNIDADES (sede/núcleo) & $\mathrm{R} / \mathrm{U}$ & Fam. & hab. \\
\hline \multirow{12}{*}{$\begin{array}{l}\text { 1. ADRIANÓPOLIS } \\
\text { Com. Bocaiuva Sul }\end{array}$} & 01. João Surá & $\mathrm{R}$ & 24 & 88 \\
\hline & a) Poço Grande & $\mathrm{R}$ & 5 & 26 \\
\hline & b) Guaracuí & $\mathrm{R}$ & 12 & 35 \\
\hline & 02. Praia do Peixe & $\mathrm{R}$ & 6 & 23 \\
\hline & 03. Porto Velho & $\mathrm{R}$ & 15 & 66 \\
\hline & 04. Sete Barras & $\mathrm{R}$ & 18 & 73 \\
\hline & 05. Córrego das Moças & $\mathrm{R}$ & 14 & 49 \\
\hline & a) Córrego Malaquias & $\mathrm{R}$ & 6 & 19 \\
\hline & 06. São João & $\mathrm{R}$ & 17 & 62 \\
\hline & 07. Córrego do Franco & $\mathrm{R}$ & 76 & 220 \\
\hline & 08. Estreitinho & $\mathrm{R}$ & 8 & 24 \\
\hline & 09. Três Canais & $\mathrm{R}$ & 8 & 22 \\
\hline \multicolumn{5}{|l|}{ 2. BOCAIÚVA DO SUL } \\
\hline Com. Bocaiúva Sul & 10. Areia Branca & $\mathrm{R}$ & 13 & 36 \\
\hline \multicolumn{5}{|l|}{ 3.CAMPO LARGO } \\
\hline Com. Campo Largo & 11. Palmital dos Pretos & $\mathrm{R}$ & 34 & 136 \\
\hline \multicolumn{5}{|l|}{ 4. CANDÓI } \\
\hline \multirow{3}{*}{ Com. Guarapuava } & 12. Despraiado & $\mathrm{R}$ & 39 & 151 \\
\hline & 13. Vila Tomé & $\mathrm{R}$ & 20 & 57 \\
\hline & 14. Cavernoso & $\mathrm{R}$ & 6 & 23 \\
\hline \multicolumn{5}{|l|}{ 5. CASTRO } \\
\hline \multirow{3}{*}{ Com. Castro } & 15. Serra do Apon & & & \\
\hline & a) Faxinal do São João (sede) & $\mathrm{R}$ & 34 & 93 \\
\hline & b) Paiol do Meio & $\mathrm{R}$ & 3 & 12 \\
\hline
\end{tabular}




\begin{tabular}{|c|c|c|c|c|}
\hline \multirow{6}{*}{ Com. Castro } & c) Santa Quitéria & $\mathrm{R}$ & 7 & 23 \\
\hline & d) Lagoa dos Alves & $\mathrm{R}$ & 6 & 17 \\
\hline & 16. Limitão & $\mathrm{R}$ & 30 & 106 \\
\hline & 17. Tronco & $\mathrm{R}$ & 15 & 62 \\
\hline & 18.1 Mamãs - núcleo Castro & & & \\
\hline & a) Imbuial (sede) & $\mathrm{R}$ & 8 & 27 \\
\hline \multicolumn{5}{|l|}{ 6. CERRO AZUL } \\
\hline \multirow{4}{*}{ Com. Cerro Azul } & 18.2 Mamãs - núcleos Cerro Azul & & & \\
\hline & b) Ribeirão do Meio & $\mathrm{R}$ & 7 & 22 \\
\hline & c) Pinhalzinho & $\mathrm{R}$ & 3 & 13 \\
\hline & d) Pinhal Grande & $\mathrm{R}$ & 1 & 3 \\
\hline \multicolumn{5}{|l|}{ 7. CURIÚVA } \\
\hline \multirow{2}{*}{ Com. Curiúva } & 19. Água Morna & $\mathrm{R}$ & 19 & 61 \\
\hline & 20. Guajuvira & $\mathrm{R}$ & 38 & 132 \\
\hline \multicolumn{5}{|l|}{ 8. DR. ULYSSES } \\
\hline \multirow{2}{*}{ Com. Cerro Azul } & 21. Varzeão & $\mathrm{R}$ & 20 & 66 \\
\hline & a) Gramadinho & $\mathrm{R}$ & 10 & 47 \\
\hline \multicolumn{5}{|l|}{ 9. GUAÍRA } \\
\hline Com. Guaíra & 22. Manoel Ciríaco dos Santos & $\mathrm{R}$ & 13 & 70 \\
\hline \multicolumn{5}{|l|}{ 10. GUARAPUAVA } \\
\hline \multirow{5}{*}{ Com. Guarapuava } & 23. Invernada Paiol de Telha & $\mathrm{R}$ & 32 & 160 \\
\hline & a) Assent. V. Socorro/Guarapuava & & & \\
\hline & b) Fundão - Reserva do Iguaçu & $\mathrm{R}$ & 19 & 95 \\
\hline & c) Periferia - Guarapuava -urbana & $\mathrm{U}$ & & \\
\hline & d) Periferia - Pinhão - urbana & $\mathrm{U}$ & & \\
\hline \multicolumn{5}{|l|}{ 11. GUARAQUEÇABA } \\
\hline \multirow{2}{*}{ Com. Antonina } & 24. Batuva & $\mathrm{R}$ & 24 & 94 \\
\hline & 25. Rio Verde & $\mathrm{R}$ & 22 & 80 \\
\hline \multicolumn{5}{|l|}{ 12. IVAÍ } \\
\hline \multirow{2}{*}{ Com . Imbituva } & 26. Rio do Meio & $\mathrm{R}$ & 33 & 103 \\
\hline & 27. São Roque & $\mathrm{R}$ & 51 & 203 \\
\hline \multicolumn{5}{|l|}{ 13. LAPA } \\
\hline \multirow{3}{*}{ Com. Lapa } & 28. Restinga & $\mathrm{R}$ & 24 & 93 \\
\hline & 29. Feixo: & & & \\
\hline & a) Rincão & $\mathrm{R}$ & 51 & 202 \\
\hline
\end{tabular}




\begin{tabular}{|c|c|c|c|c|}
\hline & $\begin{array}{l}\text { b) Maria Antonia } \\
\text { c) Campina } \\
\text { d) Pavão } \\
\text { 30. Feixo:Vila Esperança }\end{array}$ & $\begin{array}{l}\mathrm{R} \\
\mathrm{R} \\
\mathrm{R} \\
\mathrm{R}\end{array}$ & $\begin{array}{c}32 \\
1 \\
1 \\
7\end{array}$ & $\begin{array}{c}127 \\
5 \\
9 \\
34\end{array}$ \\
\hline $\begin{array}{l}\text { 14. PALMAS } \\
\text { Com. Palmas }\end{array}$ & $\begin{array}{l}\text { 31. Adelaide } \mathrm{M}^{\mathrm{a}} \text { Trindade Batista } \\
\text { Bairro São Sebastião do Rocio } \\
\text { 32. Castorina Maria da Conceição } \\
\text { Bairro Fortunato }\end{array}$ & $\begin{array}{l}\mathrm{R} \\
\mathrm{R}\end{array}$ & $\begin{array}{l}89 \\
20\end{array}$ & $\begin{array}{l}391 \\
74\end{array}$ \\
\hline $\begin{array}{l}\text { 15. PONTA GROSSA } \\
\text { Com. Ponta Grossa }\end{array}$ & $\begin{array}{l}\text { 33. Sutil } \\
\text { 34. Santa Cruz }\end{array}$ & $\begin{array}{l}\mathrm{R} \\
\mathrm{R}\end{array}$ & $\begin{array}{l}41 \\
11\end{array}$ & $\begin{array}{c}144 \\
39\end{array}$ \\
\hline $\begin{array}{l}\text { 16. S. MIGUEL DO } \\
\text { IGUAÇU } \\
\text { Com. São Miguel Iguaçu }\end{array}$ & 35. Apepu & $\mathrm{R}$ & 6 & 44 \\
\hline $\begin{array}{l}\text { 17. TURVO } \\
\text { Com. Guarapuava }\end{array}$ & 36. Campina dos Morenos & $\mathrm{R}$ & 10 & 66 \\
\hline
\end{tabular}

Fonte: GTCM (2010).

Essas comunidades ficam localizadas, principalmente, em regiões que, no passado, fizeram parte dos caminhos das tropas e próximas a garimpos e minas de ouro. Porém, estão situadas em lugares distantes, de difícil acesso e sem infraestrutura, o que acaba acarretando determinado êxodo por parte dos habitantes mais jovens em busca de melhores condições de vida.

De maneira geral, essas comunidades mantêm os padrões de produção utilizados por seus antepassados, baseados principalmente no cooperativismo e na prática de uma economia de subsistência. Os principais produtos cultivados são a mandioca - da qual se extrai a farinha feita de forma artesanal em alguns quilombos -, cana-de-açúcar, milho, feijão, arroz e vários tipos de frutas e legumes. Pratica-se, também, a criação 54 de animais, como porcos, galinhas, patos, cabeças de gado, cavalos e, em 
alguns casos, a criação de peixes. Vale ressaltar que o trabalho na roça é executado tanto por homens quanto por mulheres.

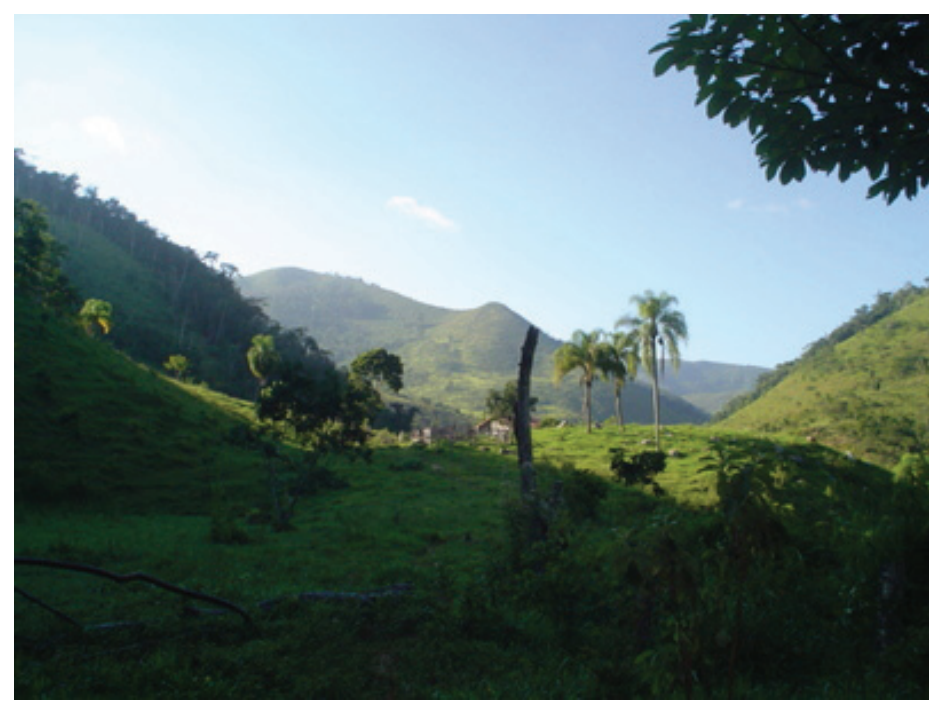

Figura 2: Foto do Quilombo de João Surá/Núcleo Poço Grande. Nesta parte há maior concentração de gado, pois existe abundância de pastagem

Fonte: Santiago Neto (2009).

Em determinadas regiões do Estado os quilombolas também praticam a coleta de frutos nativos, como em Campo Largo, no quilombo de Palmital dos Pretos, onde boa parte da renda dos moradores está diretamente ligada à extração de palmito. O etno-conhecimento ou sabedoria popular é outra das fontes de renda dessas comunidades que exploram sustentavelmente o meio ambiente. $O$ conhecimento, principalmente dos mais velhos, em relação a ervas e plantas medicinais mostra-se de extrema importância e constitui um legado passado de pai pra filho há muitas gerações.

Um sério problema enfrentado por essas comunidades é a questão da posse da terra. Como já mencionamos acima, a Fundação Cultural Palmares, juntamente com o Ministério da Cultura, é a responsável pela 
legalização e reconhecimento dessas propriedades. No entanto, no Paraná, apenas 34 desses grupos familiares foram certificados, pela Fundação, como comunidades de remanescentes de quilombos. Número este muito inferior à quantidade real desses agrupamentos. Pelo relatório do grupo de trabalho Clóvis Moura, há ainda mais 20 comunidades não certificadas e pelo menos mais 32 comunidades que carecem de visita dos órgãos oficiais, para serem reconhecidas (GTCM, 2010).

A falta de documentação para se comprovar a posse da terra dá margem a uma série de ilegalidades que, ao longo dos anos, vem diminuindo consideravelmente a área das reservas quilombolas no Estado. Segundo depoimento dos moradores mais antigos, muitas terras pertencentes a eles foram griladas, tomadas ou compradas por valores irrisórios.

Essas regiões, por estarem cercadas pelas propriedades de grandes fazendeiros, sofrem com o desmatamento na beira dos rios e com a contaminação da água e do solo por agrotóxicos, situação que afeta diretamente sua principal fonte de renda, o meio ambiente. O Vale do Ribeira é um exemplo claro desse desrespeito indiscriminado e da impunidade aos que cometem crimes agrários na região.

Pela quase que total falta de infraestrutura e assistência por parte do Estado, essas comunidades vivem totalmente esquecidas. Um dos problemas mais sérios é a falta de documentação dos moradores: muitos não têm sequer o registro de nascimento. Automaticamente, elas não existem para o Estado. Assim sendo, não têm meios de reivindicar seus direitos.

Nos quilombos a cultura afro-brasileira é preservada nas inúmeras festas desenvolvidas ao longo do ano. A romaria de São Gonçalo, romaria do Divino, mesa dos anjos, recomendação das almas e o terço cantado são tradições preservadas e mantidas no seio dessas comunidades há várias gerações. A religião, sem sombra de dúvidas, ocupa um espaço importante na vida dos quilombolas e sua expressão consiste num aspecto marcante dessas comunidades. 




Figura 3: Foto de Comunidade Quilombola. Falta de estrutura e assistência é um dos maiores problemas Fonte: GTCM (2010).

No entanto, em virtude do seu isolamento espacial, da falta de estrutura e reconhecimento por parte do Estado, assim como os demais problemas já citados, essas 'terras de preto', como são denominadas por seus moradores, correm sério risco de perderem seu legado histórico. $\mathrm{Na}$ maioria dos casos, a memória dos quilombolas mais antigos é o único documento que comprova a propriedade da terra e, sem esta, não é apenas a história que se corre o risco de perder. Nas comunidades tradicionais camponesas, como as quilombolas, as lembranças de 'tempos imemoriais' - que passam de geração para geração - devem ser consideradas inclusive para titulação de terras.

Observando o desamparo legal dessas comunidades no Paraná, concluímos que há a necessidade de o Estado intervir, de forma mais consistente, procurando formular políticas públicas de assistência a essas 
comunidades (POMARI, 2008), bem como garantir o reconhecimento e a titulação das suas terras. Preservar a história de vida e a cultura das pessoas que habitam essas comunidades é preservar uma parte da nossa história, fundamental no processo de formação da cidadania no Brasil.

\section{Referências}

FIABIANI, Adelmir. Mato, palhoça e pilão: o quilombo, da escravidão às comunidades remanescentes (1532-2004). São Paulo: Expressão Popular, 2005.

FUNDAÇÃO PALMARES. Comunidades quilombolas. Brasília, DF: Fundação Cultural Palmares, 2012. Disponível em: <http://www.palmares.gov.br/?page_ $\mathrm{id}=88$ \&estado=PR\#> . Acesso em: 25 jan. 2012.

GRUPO DE TRABALHO CLÓVIS MOURA. Relatório do grupo de trabalho Clóvis Moura. Curitiba: GTCM, 2010. Disponível em: <http://www.gtclovismoura.pr.gov.br/ arquivos/File/relatoriofinal2005a2010.pdf> . Acesso em: 22 fev. 2012.

MOURA, Clóvis. Quilombos, resistência e escravismo. São Paulo: Ática, 1987.

POMARI, Luciana. Os paradoxos das políticas públicas referentes às comunidades remanescentes de quilombos, no Estado do Paraná, Brasil. JORNADAS NACIONALES ESPACIO, MEMORIA E IDENTIDAD, 5., 2008, Rosário. Actas... Rosário: UNR, 2008.

SANTIAGO NETO, Cremilda. Situação atual da terra nas comunidades de remanescentes de quilombos e nas comunidades tradicionais negras do Paraná. Disponível em: <http://quilombosnoparana.spaceblog.com.br/2/>. Acesso em: 10 jun. 2009. 